\title{
Organizational and managerial aspects of tourist destinations branding: partnership management in the development and implementation of activities
}

\author{
Svetlana Viktorovna Grinenko*, Galina Maksimovna Romanova, Maksim Sergeevich \\ Romanov, and Nadezhda Konstantinovna Serdyukova
}

Sochi State University, Sochi, Russia

\begin{abstract}
The tourist destinations develop with the participation of a significant number of stakeholders, whose interests often do not coincide, and sometimes completely differently directed, which determines the multifactorial nature of the relationship in the scope of the set goals achieving. On the one hand, this is the development of tourism, in which the business community is interested, on the other hand, the interests of the territory administration, which interests are of a dual nature. Coordination of the interests of all interested parties - the administration, the population of the territorial entity, the business community and tourists becomes a priority in this situation. The solution to this priority task through partnership management technologies is proposed in this research. The research is based on the use of a systematic approach and technologies of management analysis and modelling. The proposed conclusion, algorithm, model can be used in the implementation of territories branding, in the formation and implementation of the tourist destination development, in the regional policy formulation in the tourism development and the local self-government development.
\end{abstract}

\section{Introduction}

Human society is set up that its development requires constant active interaction between the most diverse cells of society, which together form a complex dynamic self-developing system. Solving the problems of joint activity, which is constantly present in the modern management of social and economic systems, requires the assessment and regulation of various areas of organizing business interaction. At the same time, it should be noted the difference in the institutional forms of relationships between the state, organizations and

* Corresponding author: sveta.grinenko@gmail.com 
individuals engaged in joint activities, including the development and implementation of entrepreneurial ideas, solutions, plans and programs.

The form of economic entities association, defined as partnership [10], is aimed at implementing the process of ensuring coordinated activities in accordance with the set strategic economic and social goals. With regard to the category of partnership, it is legitimate to say about strategic partnership, since it is expected to obtain certain resources from the association itself, which presupposes achievement of individual strategic goals for each subject-participant and at the same time achieving a synergistic effect from the joint activities implementation. Among the principles of partnership, allowing to obtain the best synergistic effect, it should be noted voluntariness, common (agreed) interests, interdependence in the activities implementation, dedication to the developed common idea, joint work to achieve the designated goals, complementary support that allows to reduce risks, good communications that implement effective information exchange between participants, mutual respect and faith, free choice and equality, not causing direct harm to other firms and companies.

\section{Materials and Methods}

There are many approaches to defining the "territory brand" category, the analysis of which is not the task of this article, but a systematic approach to the correlation of the above categories determines the possibility of building branding with the use of experiential marketing technologies (Fig. 1).

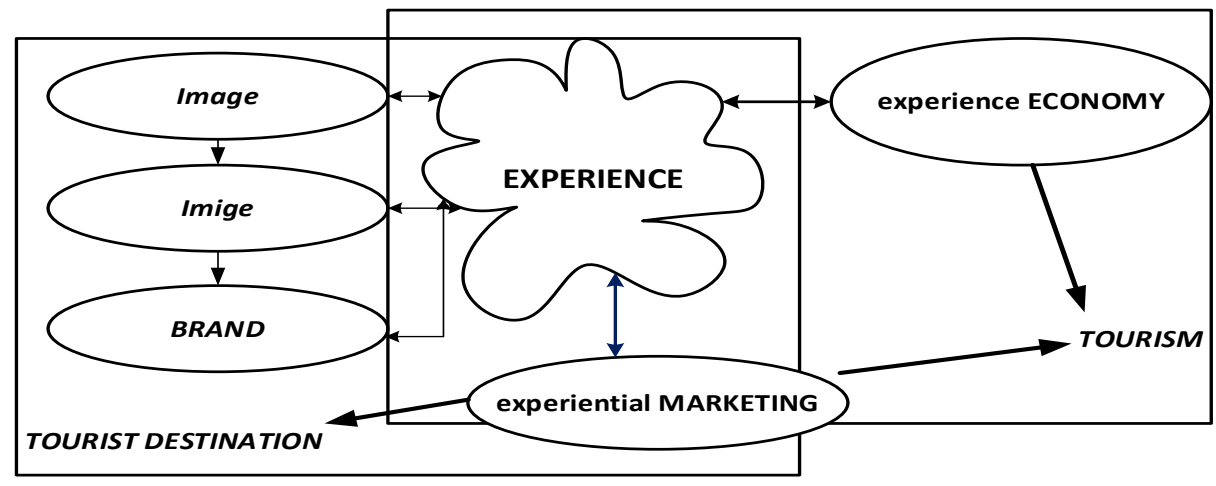

Fig. 1. Ratios of tourism experiential marketing

According to D. Ogilvy, a brand is "the intangible sum of the product properties... A brand is also a combination of the impression it makes on consumers and the result of their experience of using it" [14]. Experiential marketing as a holistic concept in the scope of the brands formation in Russian territories is the integration of the sciences of marketing, sociology and psychology based on a paradigm shift in relationships between the company and customers - the company plays the role of director of impressions, and customers play the role of "spectators" or "guests", which within the tourism and hospitality industry serves as a platform for existence. Experiential marketing technologies within the tourist destination implement a complex and multifaceted process, which consists in the need to correlate the image, reputation and brand of the territory within the interests of all stakeholders.

"The brand of the region accumulates the interests of the "stakeholders" of the region its population, investors, business, government, and is not directly focused on achieving commercial interest, but in addition to the economic function of forming the prerequisites for creating added value, it performs the most important social function - increasing the life motivation of the region residents, growth of their welfare and well-being" [7]. Furthermore, 
a brand is "the impression that the city makes on the target audience, the sum of all the material and symbolic elements that make the city unique" [3]. Also the difficulty is that sometimes in using the tools for experiential marketing, creating a brand, it is necessary to change the image of the territory in the consumers' (guests') opinion. In particular, the creation of tourist attractors in small provincial towns or villages, in industrial areas.

According to the definition of F. Kotler [12] as components of the territory brand, let us analyze the practical experience of territories in the experiential marketing implementation to promote the destination. Among the components of the territory brand, a unique emotionally positive image was named - according to the research of the experiential marketing founder, Berndt Schmitt, Stanford University professor, experience directly affects the formation of loyalty, turns consumers into "brand advocates" based on the built emotional connection between the brand (product or service) and the consumer [18]. Building such an emotional image for a destination is associated not only with various spheres - it is the activity of tourism and hospitality enterprises, this is the territory itself that should be equipped, this is the history of the territory, this is the population of the territory, which is also the bearer of the brand. This is due to the fact that the source, which is an incentive for emotions, can be both internal states of the nervous system and external conditions, events, situations, processes [12], which are determined by the tourist destination. And the ratio of all the components form a holistic image of the territory in the consumer's mind - Baikal, Moscow, Sochi, Veliky Ustyug - for everyone, even the names of the territories themselves form a certain emotional image that characterizes it, formed from knowledge or stay in the named area. It also logically flows into a promise of needed qualities to territory consumers (guests) - Baikal - beauty, ecology, water, untouched nature; Moscow - rhythm, history, shopping, friends, etc .; Sochi - sea, sun, rest; Veliky Ustyug - a fairy tale, winter, Ded Moroz (subjective author's associations of consumer qualities of the territory). And finally, the increased subjective value of the territory, based on the guest's preferences. As an example mountaineering as a type of mountain tourism - work, stress, lack of everyday comfort, etc. vs overcoming, summit, beauty, etc. We can distinguish a segment of guests for whom the subjective value of mountain areas will be a priori higher than any others.

Arrival of the customer (guest) to the territory (to the accommodation facility, catering organization, airport, etc.) is the next stage of communication. Undoubtedly, by this time the tourist had already formed a certain expectation, which the territory must justify, leave exactly that "emotional trace" that will subsequently make him return. One wrong step and everything that was built before will not just be destroyed. Psychologically, it will become not just a disappointment, but a point of irritation, dislike, critical reviews and recommendations. Therefore, the task of experiential marketing is not only to create the desired perception, but also subsequently to leave and maintain the intended impression.

According to the classics, "impression is marketing" [16], and "marketing is the ability to make a brand a favourite of customers" [12]. These statements today can be considered basic in the business transformation in the context of the transition to the experience economy, which affects not only what we consume, but also how we feel in the process of purchasing and using a product or service. A general analysis of the situation with the implementation of the principles of experiential marketing in the tourism organization in Russia in the promotion of tourist destinations and tourist and recreational complexes, of course, requires a more detailed assessment, but it already indicates the need and priority of the task of territories branding for the development of domestic and inbound tourism, which, also certainly has great potential. It should be noted that a number of regions and cities are already taking their first steps - mainly this is the development of external brand attributes a logo, slogan, brand book, but almost no one implements a set of activities, the use of a single logo by all tourism-forming enterprises, interaction with the local community, which should to be the next step in developing a brand of a tourist destination in conjunction with 
creating a story that is attractive to guests as part of the development of domestic and inbound tourism.

It should be noted that all elements of a territory brand require not only organizational and managerial measures, which are usually initiated by the territory administration, but also the active participation of the local business community and the unconditional support of the population. In this regard, it is necessary to propose measures to create effective cooperation and partnerships between all stakeholders in the tourist destination development.

According to $\mathrm{M}$. Porter [17], improving business and national competitiveness is increasingly a process of multilateral cooperation, which involves government bodies, companies, educational institutions and structures - institutions of cooperation. Such "institutions of cooperation" play an important role as intermediaries, organizing and executing collective action, ensuring more effective interaction among the stakeholders of a particular tourist destination.

The "infrastructure of cooperation" concept [8] was proposed by M. Gibson and is based on the formation of "ways in which people and organizations can come to each other to exchange ideas, solve problems and create partnerships". This implies civic leadership, public-private partnerships, identification of a regional development strategy, and an appropriate set of "institutions of cooperation".

Structural and institutional ties of economic entities have a fundamental justification in the form of a mechanism for coordinating the interests. The coordination of the socioeconomic interests of the subjects of a tourist destination requires a conceptual and theoretical justification due to its specificity, since the interests of these subjects determined by the classical development paradigm have a clear hierarchical structure and are of a public or mixed nature [11].

The foregoing actualizes the development of a mechanism for coordinating interests in a specific problem area in order to form an effective system of structural and institutional ties in the development system of a tourist destination based on the territory branding (Table. 1).

Table 1. The interests of socio-economic subjects of strategic partnership in the tourist destination development*

\begin{tabular}{|c|c|}
\hline Subject & rests \\
\hline \multirow{2}{*}{ 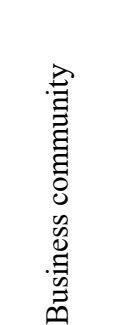 } & $\begin{array}{l}\text { Private: } \\
\text { cost reduction; } \\
\text { improving the quality of products and services provided; } \\
\text { increasing the enterprise profitability and cost effectiveness; } \\
\text { timely vacancy turnover by competent specialists. }\end{array}$ \\
\hline & $\begin{array}{l}\text { General: } \\
\text { development of production techniques and technologies and the provision of } \\
\text { services based on research; } \\
\text { increasing the level of innovation orientation of the enterprise. }\end{array}$ \\
\hline \multirow{2}{*}{ 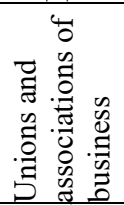 } & $\begin{array}{l}\text { Private: } \\
\text { improving the quality of products and services provided; }\end{array}$ \\
\hline & $\begin{array}{l}\text { General: } \\
\text { balance of the labour market; } \\
\text { increasing the level of innovation orientation of the economy. }\end{array}$ \\
\hline 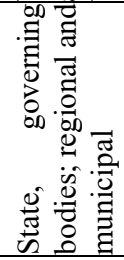 & $\begin{array}{l}\text { Private: } \\
\text { obtaining both economic and social effects from the tourist destination } \\
\text { development, the use of tourist facilities and infrastructure; } \\
\text { increasing the level of demand, recognition, development of the territory brand; } \\
\text { introduction of innovations, the latest techniques and technologies into the } \\
\text { economy, educational system of the region (city) - tourist destination; } \\
\text { reducing the costs of the region development. }\end{array}$ \\
\hline
\end{tabular}




\begin{tabular}{|l|l|}
\hline & $\begin{array}{l}\text { General: } \\
\text { socio-economic development of the tourist area; } \\
\text { balance of the labour market of a tourist destination; } \\
\text { reducing social tension; } \\
\text { increasing the level of innovation orientation of the economy. }\end{array}$ \\
\hline \multirow{2}{*}{$\begin{array}{l}\text { Private: } \\
\text { receiving quality services; } \\
\text { obtaining the opportunity to receive recreational, tourist services of a high level } \\
\text { within the country; } \\
\text { achieving the desired level of wages; } \\
\text { socio-economic development of the region (city) - a tourist destination. }\end{array}$} \\
\cline { 2 - 2 } $\begin{array}{l}\text { General: } \\
\text { reducing social tension; } \\
\text { decreasing the unemployment rate; } \\
\text { increasing the level of wages. }\end{array}$ \\
\hline \multirow{0}{0}{}
\end{tabular}

* Compiled by the authors based on research materials

It stands to mention a number of contradictions arising in the allocation of general and private interests based: firstly, on the opposing interests of various socio-economic groups; secondly, on the difference in general and private (individual) interests.

It is generally accepted that tourism creates the incentives necessary for the effective management of a tourist destination and has a minimal physical and social impact on the territory. For these reasons, the interaction between people, business and tourism has received considerable attention in the development of sustainable development initiatives through partnerships at the regional and municipal levels. However, since tourism is a complex activity involving various stakeholders and environmentally and economically fragile territories, in practice it is difficult to satisfy a range of goals and interests, including in the development of a destination brand, which can be harmonized using partnership management approaches.

The complexity and uncertainty of managing the tourist destination development requires an assessment of tourism in order to identify the reasons that impede the implementation of the goals of the participating stakeholders. At the same time, it is important to select the appropriate assessment parameters, since the natural and socio-economic systems of the tourist destination require specific approaches based on the theory of sustainable development. The local community is regarded as the central nexus of tourism in order to maximize both environmental and economic and social sustainability, which often creates conflicts between objectives and the conservation of recreational, cultural and historical resources in the tourist destination management.

\section{Results and Discussion}

Developing a territory brand according to the principles of sustainable tourism requires specific policies that must be implemented in order to promote the balanced development of the destination, provide the necessary infrastructure for tourism development, avoid negative impacts on nature and ensure that visitors understand the values of the protected area [6 ].

Conflicts between stakeholders arising from divergent goals, values and problems are associated with the fact that the tourist destination management is aimed at preserving natural, cultural, historical and other resources, while travel companies and the local population call for their use for tourism purposes which should guarantee their well-being. For these reasons, when planning sustainable tourism within a tourist destination, approaches should be developed to form partnerships between municipalities, travel companies and other organizations in order to ensure the long-term application and compliance with the goals of 
sustainable development of the established policy [2]. The creation of such partnerships has a number of benefits, such as increased efficiency and productivity, innovation and stimulation of sustainable development, stimulation of initiatives to conserve resources and infrastructure, promotion of mechanisms for joint decision-making and conflict resolution [4]. The system of participation in planning the development of the territory, branding has been proposed as a best practice to facilitate the establishment of partnerships between the territory and the local and business community [1].

In this case partnership management acts as a system for organizing cross-scale interaction. Within the LIFE project [15] aimed at restoration and sustainable management of priority habitats, a methodology based on partnership in the process of tourism development in a protected natural area was proposed in the context of the sustainable development theory.

Despite the fact that this project deals with the tourism development within the protected areas, this mechanism corresponds to the development of each tourist destination in accordance with the principles of sustainable development, as well as the preservation of natural, recreational, historical, cultural resources.

At the same time, the preparatory stage contains, firstly, meetings with stakeholders organizations and enterprises - potential partners in the destination attractiveness management system based on branding to determine the potential of stakeholders and alignment of interests. As a result, initiatives are being formed to promote sustainable tourism, a program is proposed to build partnerships with all relevant institutions to advance the process. These can be departments of the relevant regional and municipal authorities, enterprises and associations of tourism and related industries, representatives of local government. The result of this stage should also be the creation of a backbone centre responsible for information and communication support of the partner network.

Secondly, a complete analysis of the current tourist, environmental and socio-economic situation in the researched area should be performed, including technical tasks, such as reviewing bibliography and conducting field work, and organizational tasks, such as questionnaires, meetings and other methods of expert assessments. The expert analysis results are compared with those obtained from bibliographic information and the results of field work. Travel companies should also be involved in the analysis to build a profile of visitors to the tourist destination, as well as identify opportunities, challenges and suggestions for improving tourism activities. One should also consider building a territory identification model in order to form an effective and sustained brand of the territory.

The next step is the presentation of the results obtained, discussion of the document on diagnostics and the working groups formation to conduct a simplified SWOT analysis in accordance with the goals of the LIFE project. At the end of the session each group presents its conclusions, which are discussed, which allows to define a clear common vision of the sustainable evolution of tourism in the researched area, incl. identification of walking routes, thematic routes, events, activities and products that allow to discover the natural heritage, culture, traditions of the territory, which will further form the basis for brand development.

Next, the process of defining a strategy is performed by the team, which analyzes opportunities, problems and proposals by dividing them into topics and defining general and specific goals for each of them. After that, the strategy for the territory development, as well as the brand project and the brand book, are presented for discussion to make adjustments and align the interests of the project stakeholders. In the process, the goals can be supplemented, the priority of these goals can be established, the goals are agreed with all participants, the distribution of responsibilities and necessary activities. If necessary, new partners are included in the process and a final action plan is drawn up.

The presented process should be a continuous process with annual analysis and revision of the action plan, as a result of adaptation of goals and actions to real changes. This ongoing 
process also allows any stakeholder to be included in the action plan at any time. In this case, two aspects should be considered - adjusting the strategy and maintaining, supporting and developing the brand.

It is necessary to highlight the special role of tourism-related companies in solving the problems of the strategy. Participation in a brand building and promotion project provides some benefits for these companies in terms of promotion in exchange for their contribution to the action plan. Each company must identify three voluntary actions that correspond to the project objectives over the next three years, which can be seen as a de facto partnership between travel companies and tourist destination administrations, regional and municipal authorities.

As a practical case for the implementation of stakeholder partnership management at the tourist destination level, we can consider the system of promoting the brand of a tourist destination in the digital tourism market. Figure 2 shows the stakeholders of the tourist destination promotion system and the promotion channels used. It is important that information for target consumers of a tourism product in the digital economy is communicated through modern tools and channels. Moreover, an important advantage of digital tools is its interactivity, the presence of a "digital footprint" of the consumer, with the help of which it is possible to set up targeted advertising and promotion of the destination and services of suppliers.

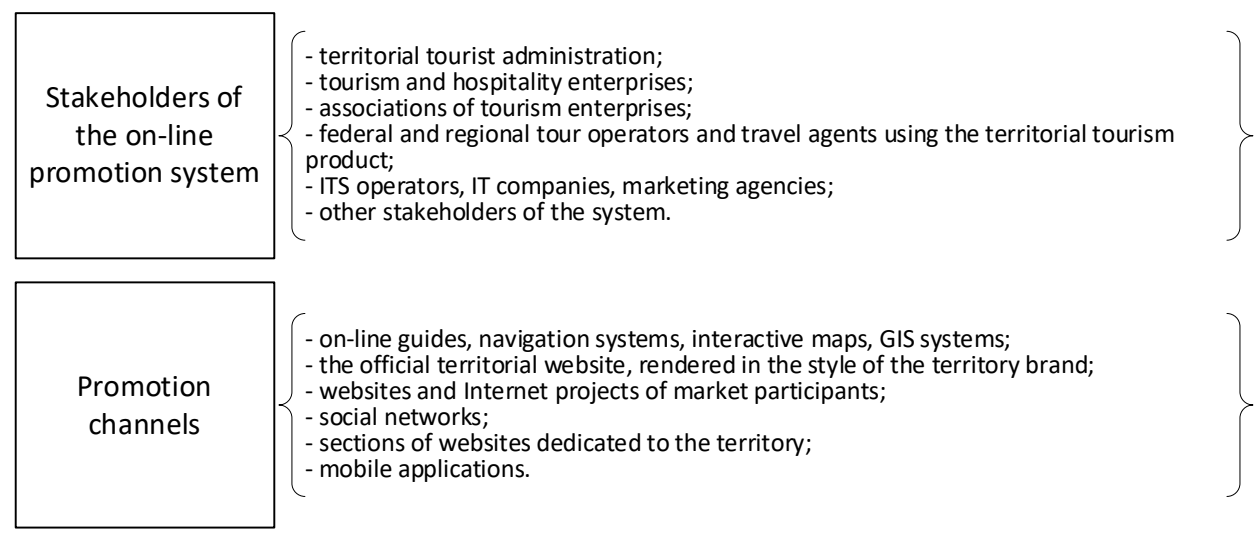

Fig. 2. Stakeholders and channels in the system of Internet promotion of a tourist destination (compiled by the authors)

A systematic approach to organizing promotion in general and Internet promotion in particular is important. Destination branding acts as a connecting link in the promotion system, which integrates all tools into a single information flow that affects the consumer. The image of a destination, for example, Sochi, takes visual outlines and affects potential customers, creating communication based on a recognizable image and personal communication with the consumer through a slogan. It's just as nice to wear branded clothes, so it is nice to be at a branded resort. The Sochi brand was fashionable and became fashionable and recognizable again.

The criteria for the effectiveness of the project implemented according to this algorithm are: the number of stakeholders, the strategy and action plan, and the application of the plan during the first year. Further, the effectiveness of the brand maintenance, increasing the attractiveness and recognizability of the territory, and the growth of the tourist flow are considered.

This system of building a partner network is necessary because the leaders of the destination cannot solve all the problems that can affect the ecological and socio-economic 
situation, especially when they occur from the outside. The degree of control is characterized by three levels:

1. The administration has direct control over the situation and, thus, can minimize any negative consequences;

2. The administration may have an indirect influence and certain control over the activities of others (for example, it may prohibit the business community from certain activities);

3. The administration can indirectly influence other stakeholders, but does not have the ability to control, which requires the development of joint approaches based on partnerships with all stakeholders, which can help it to achieve its goals.

Voluntary agreements between the administration of tourist territories and partners are widely used. They arise at the initiative of the administration, regional or municipal authorities, tourism organizations or a certain group of stakeholders that are interested in the tourist area development. However, success depends on a good understanding of the perspectives of other stakeholders. Therefore, the leaders of protected areas and their employees in implementing the proposed algorithm should convince other stakeholders to cooperate in the protected area, and also do it in their own interests. The basis for such voluntary agreements can be, in addition to the developed strategy for the improvement of the destination, the brand and activities to promote the destination.

The true economic value of a tourist territory is the amount of the profit received from the use and the amount not received in the process of use. In this case, the effect obtained can be direct - market indicators - or indirect - social and other non-market indicators, as well as unused value.

Tourism is considered a direct use of the territory, but visiting the territory affects other values. Economic Impact Assessment assesses the cost of all financial transactions, stakeholders associated with the protected area and their impact on local, regional or national economies. The impact can be measured by GDP, indicators of labour income, or the number of jobs created within the destination.

This determines the importance of the results of economic benefit studies to stakeholders at appropriate levels of detail:

- a full study of economic benefits and costs is valuable for the territory itself, as well as for state authorities, associations and unions of enterprises in the real sector of the economy, since they need to know the range of economic benefits that tourism brings to society;

- summary data is useful for regional and municipal authorities, organizations and enterprises operating in the tourism field;

- a brief summary of the economic indicators of the tourist destination use may be of interest to visitors - guests of the territory.

Conclusions

To implement the presented mechanism, it is required to create a backbone centre that implements information and communication functions, which will serve as a platform for coordinating the interests of stakeholders, building links between them within the sequence "interaction - cooperation - partnership", provision of consulting services for the formation of strategic partnerships, preparation of business plans, execution of contracts, etc. The Centre for Strategic Partnership will become the backbone as the basis for network-centric interaction, which implies the implementation of:

firstly, the dense interaction of various socio-economic actors involved in integration interaction at all system levels in a pointwise manner (in the right place at the right time);

secondly, socio-economic subjects with opposing interests are considered as nested levels of a complex system (governing bodies, economy and production, infrastructure, labour resources); 
thirdly, interaction is performed in three spheres of activity - physical, informational and intellectual.

The concept of network centrism in partnership management allows to form a system that implements the general strategic goals of integration based on the following factors:

1. Improving the quality of management and the formation of strategies through the accumulation and development of knowledge, foresights, forecasts and synergistic effects in the foresight mode:

2. Increasing the speed of management (making management decisions, coordination and control).

3. Creation of a material, technical and methodological base, including an information and communication environment, resource support for the justification and implementation of projects, selection, training, and practical training of personnel

4. Increasing the control system reliability and stability.

Finishing the above, we can draw the following conclusion: an integration infrastructure adequate to modern economic conditions in the context of the effective use of the tourist destination resources based on the growth of its attractiveness, recognition, brand development, is based on the coordination of the interests of economic entities, is a selforganizing, non-linear, non-equilibrium dissipative structure providing all partners with the general pace of development and the maximum possible synergistic effect in the system of partnerships in accordance with the sequence "interaction - cooperation - partnership".

\section{References}

1. Bill Bramwell, Vicky Mellon, Journal of Sustainable Tourism, 17, 191 (2009)

2. Tazim Jamal, Amanda Stronza, Journal of Sustainable Tourism, 17, 169 (2009)

3. T. Moilanen, S. Rainisto, How to Brand Nations, Sites and Destinations (2009)

4. S. Pfueller, Xuan Zhu, Paul Whitelaw, Caroline Winter, Spatial Mapping of Community Values for Tourism Planning and Conservation in the Murray River Reserves (2009)

5. M. Porter, Ch. Ketels, U.K. Department of Trade and Industry, Economic and Social Research Council (2003)

6. Russell Staiff, Robyn Bushell, Annals of Tourism Research, 31, 723 (2004)

7. E.Yu. Bazhenova, Terra Economicus, 11(3), 2 (2013)

8. M. Gibson, A.Yu. Afonin, University management: practice and analysis, 4 (32) (2004)

9. S.V. Grinenko, Organizational and managerial modeling of the scientific and educational infrastructure of the professional community: from interaction to cooperation and partnership (2009)

10. S.V. Grinenko, Terra Economicus, 7(3-2) (2009)

11. S.V. Grinenko, Natural Humanitarian Research, 25 (3), 58 (2019)

12. F. Kotler, Marketing from A to Z - M. (2020)

13. N.S. Martyshenko, Economic Sciences, 62, 143 (2010)

14. David Ogilvy, Advertising Industry, https://adindustry.ru/

15. Official website of the European Union, http://ec.europa.eu/

16. B. Joseph II. Pine, The experience economy. How to turn a purchase into an exciting action, 293 (2017)

17. R.M. Prytkov, Economic Sciences, 10 (35), 126 (2007) 
18. B. Schmitt, Experiential Marketing: How to get customers to sense, feel, think, act, relate to your company and brands (2001) 